IN-DEPTH SURVEY REPORT:

CONTROL TECHNOLOGY ASSESSMENT OF UNIT OPERATIONS EMPLOYED IN ORAL COATRACEPTIVE TABLET MAKIAG OPERATIONS

AT

Ortho Pharnaceutical Corporation

Raritan, New Jersey

REPORT WRITTEN BY:

Mazen Y. Anastas, Ph.D.

Paul E. Caplan

Phillip A. Froeblich

REPORT DATE:

November 1983

REPORT NO.:

105-13

\author{
NATIONAI INSTTTUTE FOR OCCUPATIONAL SAFETY AND HEALTH \\ Division of Physical Sclences and Englneering \\ Engineering Control Technology Branch \\ 4676 Columbia Parkway \\ Cincinnat1, Ohio 45226
}


PLANT SURVEYED:

STANDARD INDUSTRIAL CLASSIFICATION CODE:

SURVEY DATE:

SURVEY CONDUCTED BY:

EMPLOYER REPRESENTATIVES CONTACTED:

EMPLOYEE REPRESENTATIYES CONTACTED:

ANAIYTICAI WORK PERFORMED BY:

STATISTICAL ANALYSIS BY:
Ortho Pharmaceutical Corporation Raritan, New Jersey

Chemical and Allied Producta Sector (SIC 28)

June 13-17, 1983

Mazen Y. Anestas, Ph.D.

Paul E. Caplan

Fhillip A. Froehlich

David E. Will1ans, Director of Operations

Christopher A. Sul11van, Plant Manager Steven J. Martinez, Production Mangger Sanuel P. Epstein, Manager, Safety and Benefits

Dennis Canavar, Manager, Project and Process Engineering

John M. Kelly, Senior Project Engineer

Robert J. Kretvix, Senior Industrial Hygienist

Harry A. Kaufman, Manager, Mafntenance

None

Charles Neumelster, NIOSH

Stanley Shulman, Ph.D., NIOSH 


\section{INTRODTCTION AND SUMMARY}

The Occupational safety and Health Act of 1970 (PL 91-596) was enacted to "assure safe and healthful working conditions for men and women." The Act established the National Institute for Occupational Safety and Health (NIOSH), which is now in the Department of Health and Human Services. NIOSy was charged by this Act to conduct research and develop criteria for preventing exposure of workers to harmful chenlcal and physical agents. In response to this legislative mandate, NIOSH has conducted major programs to document, develop, and disseminate information regarding the recognition, evaluation, and control of such agents.

In 1976, NIOSH instituted a major effort to prevent occupational health problems through the assessment and application of control technology in the workplace. This control technology research program involves engineering assessments in which effective options for the solution to employee exposure problems are evaluated and documented. The major goals of the assessment program are to establish a catalogue of solutions by documenting successful applications of control measures, and to foster the more widespread application of these solutions through technology transfer.

Oral contraceptives (OC) have been selected for study because they represent tha largest single use of estrogens, and because they are processed using rather typical pharmaceutical technology. From a control technology point of view, the biological potency of these materials has led manufacturers to implement rigorous control systems. The unit processes employed in manufacturing (preweighing of actives and excipients, mixing and granulation, tableting, and packaging) are comon within the pharmaceutical industry. A systematic characterization of the controls used in DC tablet manufacturing is therefore beneficial in batch manufacturing frocesses wherein sinflar unit operations and active Ingredients of similer potency are employed, both within and outaide of the $O C$ processing operations.

In the late 1970's, Ortho Pharmacentical Corporaticn (OPC) designed and built a new plant including a processing facility for the manufacture of $O C$ 
tablets. The process includes facilities for 1) prewefghing of active ingredients, 2) wet mixing of active ingredients and exctpients and drying to produce a granulation (processing), 3) compression of the granulation into tablets (tableting), and 4) packaging.

This report documents the concepts and principles underlying the health hazard controls associated with the nanufacturing operations. 
FRODUCTS

$O P C$ Danufactures several types of unit dose $O C$ tablets at the Raritan facility. orthom Novum ${ }^{(R)}$ tablets contain 1 milligras norethindrone (NoR), but their potency with respect to mestranol (MES) varies. Ortho-kovum (R) $1 / 35,1 / 50$, and $1 / 80$ contain 35, 50, and 60 micrograms of mestranol respectively. Also produced are modicon $(R)$ tablets which contain 35 rulcrograms of ethynylestradiol (EE) and 500 micrograms of norethindrone. The production schedule during the NIOSH survey is given in Table 1.

Table 1. OC Praduction Schedule During NIOSH Survey

\begin{tabular}{lcccc}
\hline & & & \\
Date & Processing & Tableting & T-1ine & V-line \\
\hline $6 / 13 / 83$ & - & $1 / 80$ & $1 / 50$ & $1 / 35$ \\
$6 / 14 / 83$ & $1 / 35$ & $1 / 80$ & - & $1 / 35$ \\
$6 / 15 / 83$ & $1 / 35$ & - & $1 / 50$ & $1 / 35$ \\
$6 / 16 / 83$ & - & Modicon & $1 / 50$ & - \\
$6 / 17 / 83$ & - & Modicon & & - \\
\hline
\end{tabular}

\section{FACILITY LAYOUT}

A plan view of the $D C$ manufacturing facility is given in Figure 1 . Acces to the high risk areas lpreweighing ( $P-415)$, processing (P-423), and tableting (P-429) i is through an entrance doot adjacent to the men's locker room (P-418) after approprtate personal protective equipwent (PPE) has been donned. Egress from these high rlsk areas is through the water shover and tack to the men's locker room. Exclptents are brouglit to the Material staging Room (P-416) while actives are handled in the Preweign Room (P-415).

There are two packaging lines - the $T-1$ ine (P-405) and che V-1ine (P-406A). 


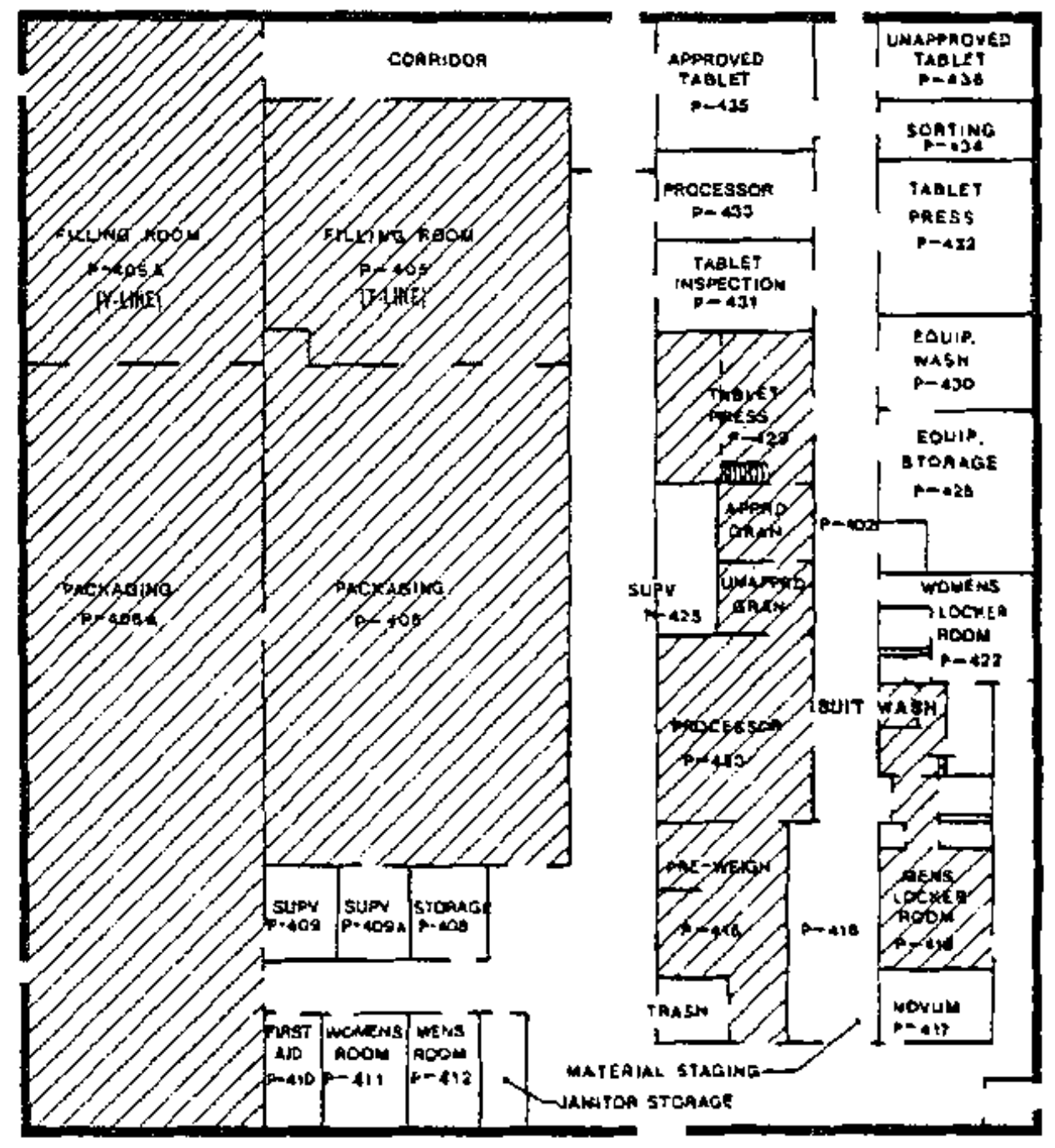

Figure 1. Plan View of Ortio Finamaceutica1 Nowum Conglex Note: Shaded Areas Were Active During NIOSH Survey 


\section{PREWEIGHING OF INGREDIENTS}

Active ingredients sre weighed in the preweigh room. Rather than weighing out ingredients one batch at a time, ingtedients for many batches are weighed out according to the projected schedule of production. One worker weighs the batches using an electronic balance located in a hood (to be described later). The material for each batch is placed in a container lined with a clear plastic bag.

Excipients constitute more than 99 percent by weight of the batch. They are preweighed fnto fiber drums at a location outside the steroid manufacturing facility and are brought to the Material Staging Room.

PROCESSTNG (GRANULATION)

Excipients in the Material staging Room are transferred from drums to the $\forall$-Blender by use of a VAC-U-MAX $(R)$ system (VAC-U-MAX Corporation). A schematic of the system is shown in Figure 2. When transferring powder from the drum to the $\nabla$-Blender, vacuum is developed by the vactum pump and powder mixed with air moves through the Iines to the blender. The small amount of powder that does not settle in the tlender is intercepted by the canvas filter. As more powder deposits on the filter, it becomes plugged - thus inhibiting aixflow. In this case, "blowback" of the filter is necessary. This is accomplished automatically by closing the pinch valve and turning the four-way valve such that outside air flows toward the filter housing. The flow is induced by the vacuum which existed duxing the first part of the cycle. The sequence (blowback and material flow) 1 s controlled by a timer. To protect the vacuum pump from being deadheaded during blowback, the safety valve opens when a preset vacuum Ievel is reached in the suction side of the pump.

Norethindrone is added to the V-Blender dfrectly. MES or FE is dissolved in a prewelghed quantity of solution in a sulil mixing tank. The EE or MES container is rinsed with solution. A positive displacenent pump is used to transfer the solution of active to the $V$-Blender. 


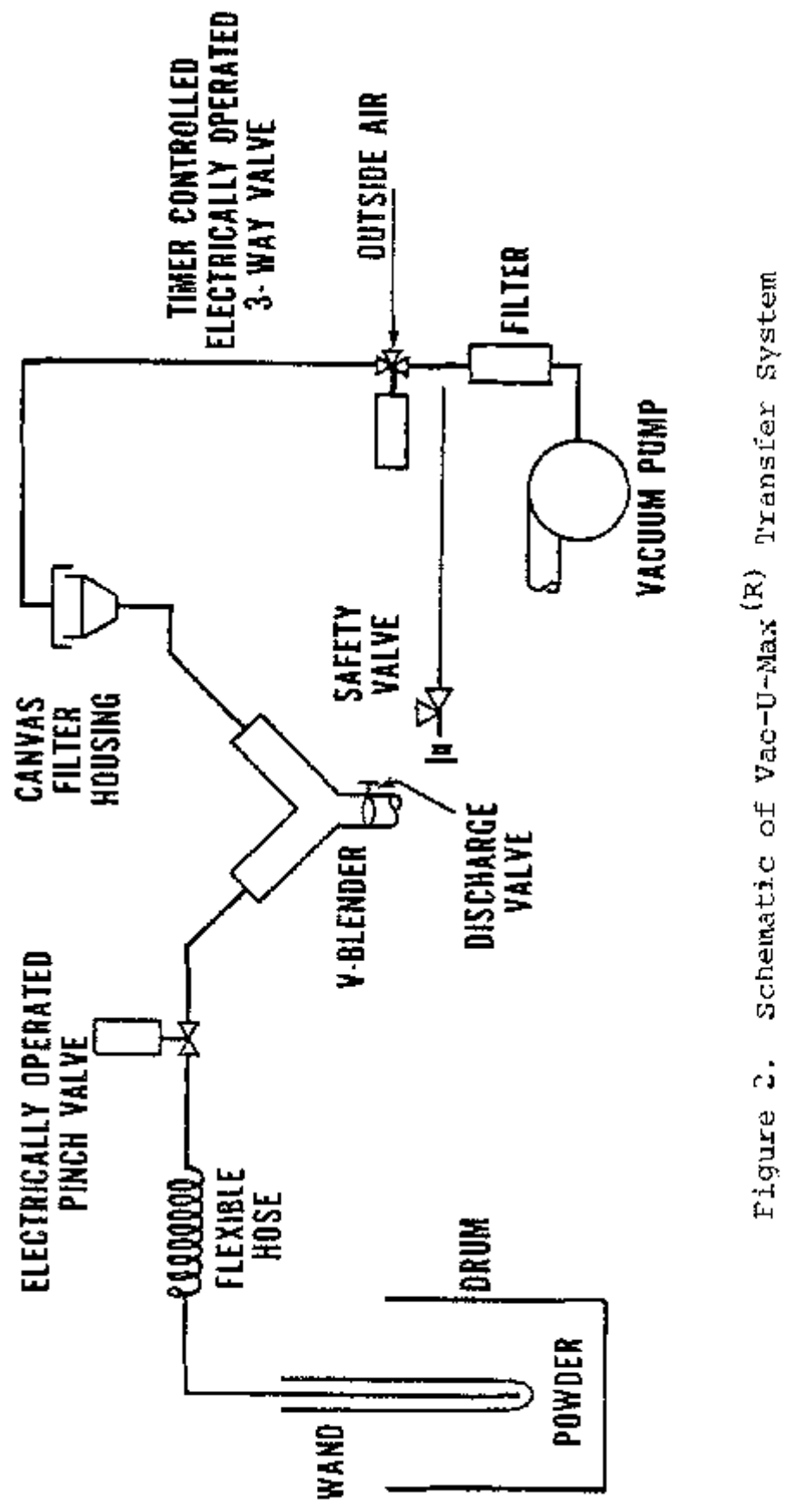


The mixing and drying scheme for production of granulation used at opC is shown 1n Figure 3. The solution of actives MES or EE is dispersed through other ingredtents by pumping under pressure through the "Intensifier bar" of the $v$-Blender while the latter is rotating. The liquids in the wet granulation are removed by passing steam-heated fluid through the V-Blender jacket. The vapor produced is withdrawn by vacuum (pump) and is condensed ith two condensers in series as shown in Figure 3 . Chllled water is passed through the condenser jackets. The worker uses a "thief" to sample granulation from both sides of the blender when drying is complete. $A$ loss-on-drying test is performed on these samples. After it has been detexuned that drying is cowplete, a "capsule" is rolled underneath the blender to receive all of its contents. The capsule is attached to the $V$-Blender before the dump valve is opened, naking it essentially a closed system.

One worker operates the system during the shift. However, help from one or two additional workers is required at the beglining when transferring excipients and actives to appropriate pieces of equipment and at the end when emptying the $V-B l e n d e r$ contents into the capsule. In the latter instance, a worker on top of the blender uses a tool to push residual granulation into the capsule.

\section{TABLETING}

The tableting operation is performed in a room dedicated for this purpose. One worker operates the tableting machine and performs quality control testing which includes the perlodic monitoring of tablet weight and friability.

The tableting machine used at the $O P C$ facility is a lanesty rotapress ik IIA Eold in the U.S. by Thomas Engineering, Hoffman Estates, Illinois. The machine and associated equipment are shown schematically in Figure 4. Granulation is fed to the rotary press from a capsule that is inverted over the feed chute which terminates into a flange at floor level in the mezanine. Figure 5 is a photograph of the capsule in place. Grantation in the chute is sed to the two machine hoppers by screw convegors. A force-flow 


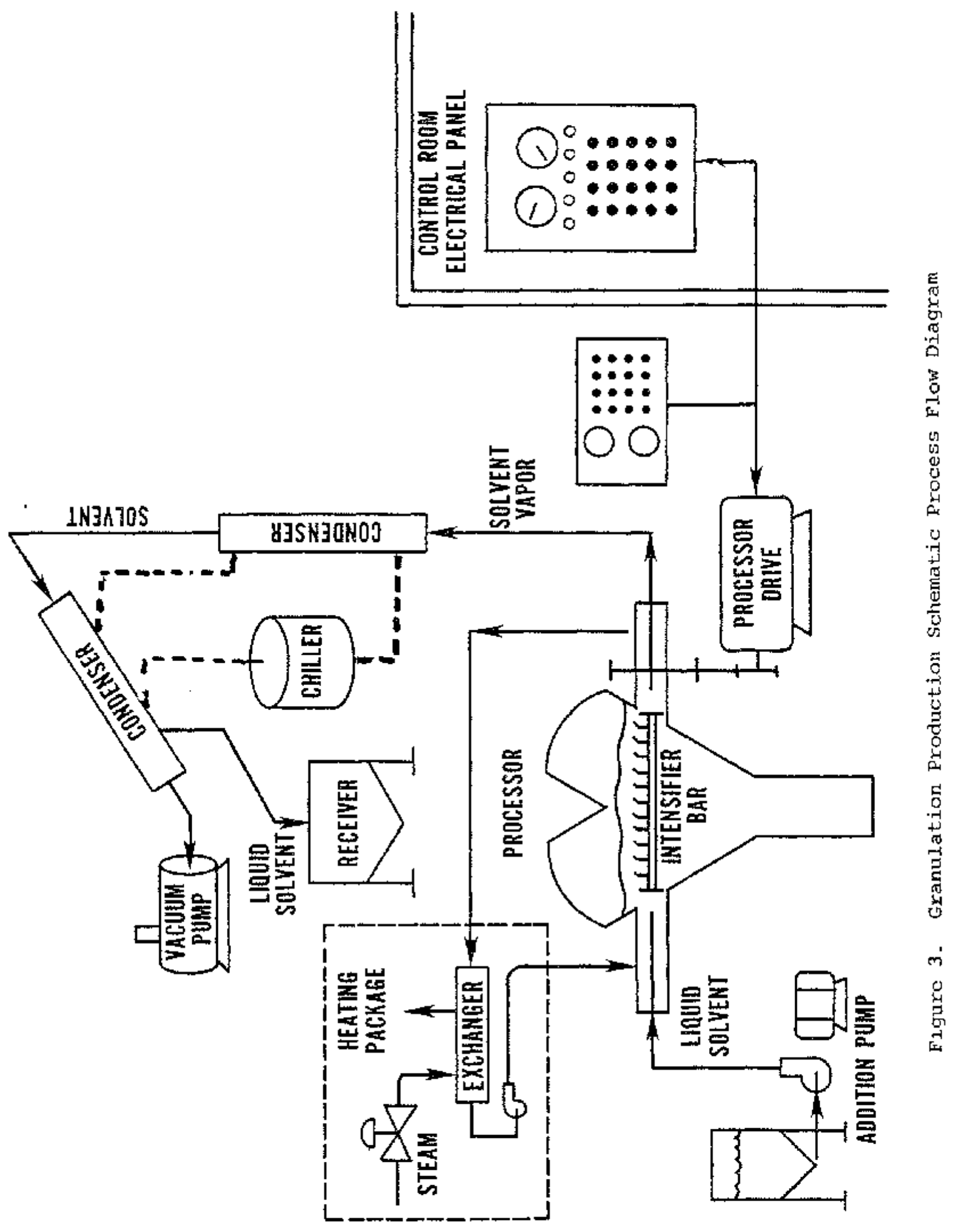




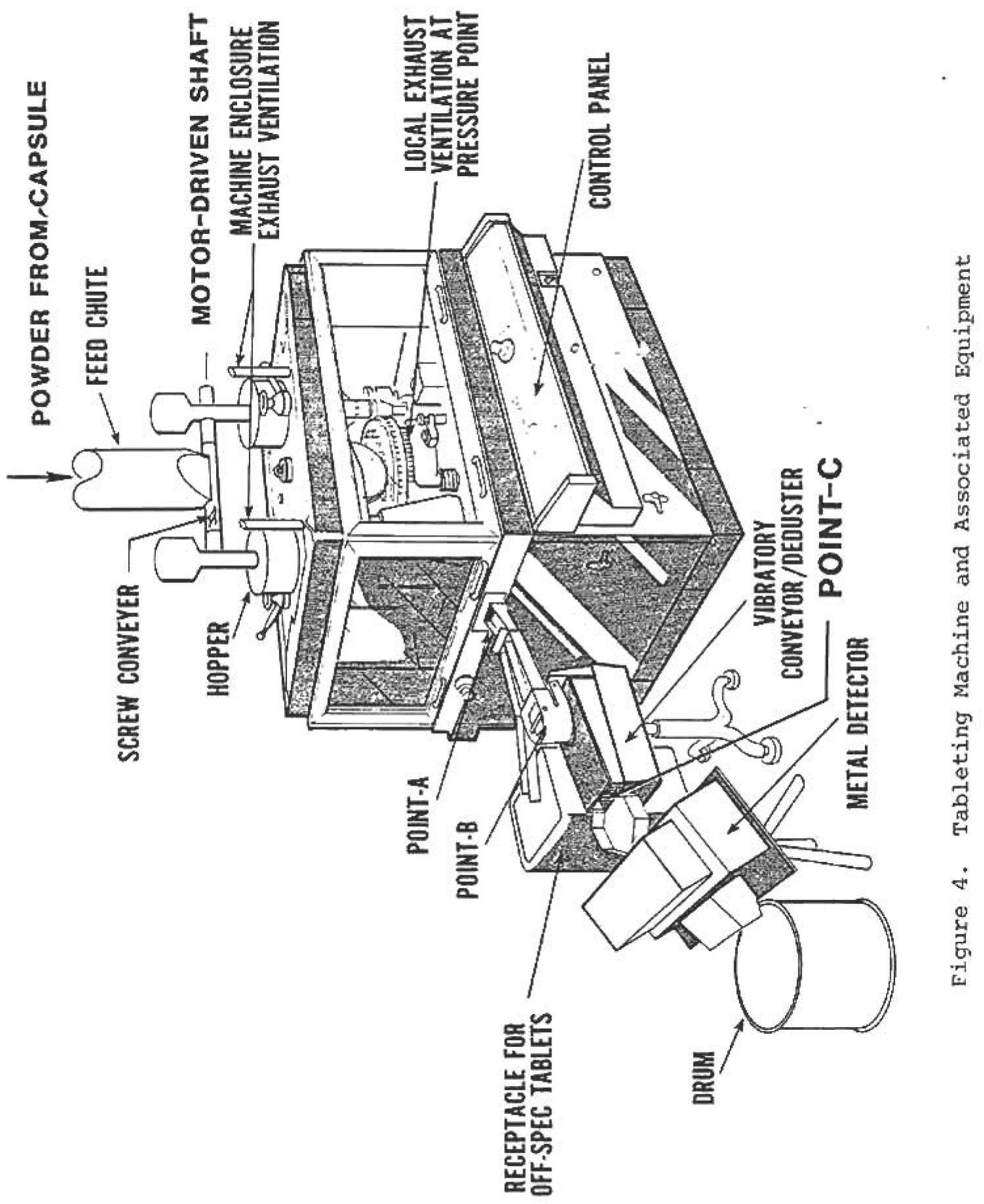




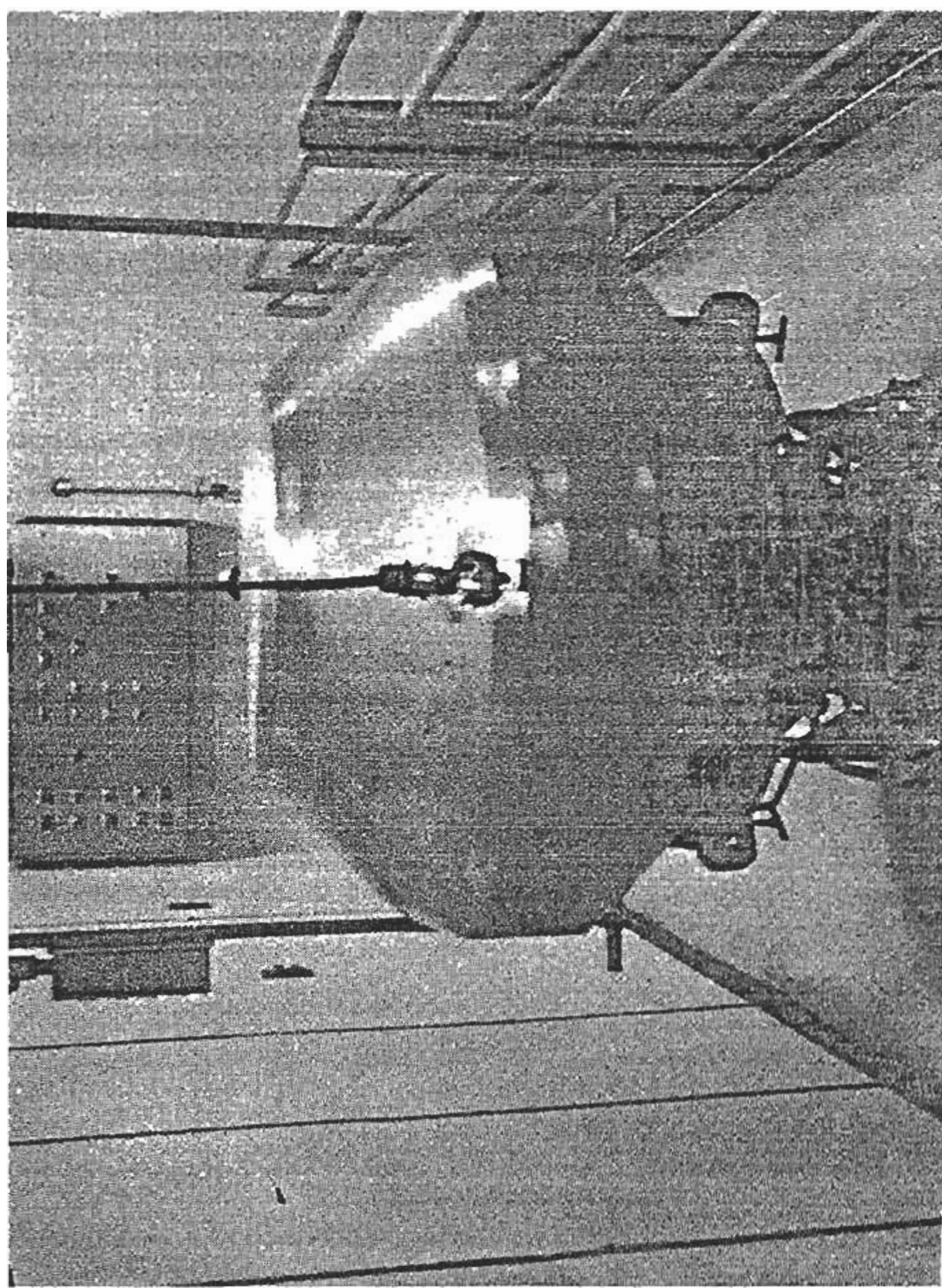

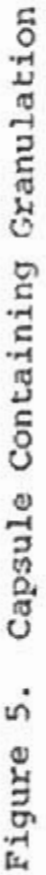


feeder (shown in Figure 6) accomplishes feeding of the dies and scraping of excess powder. From this point on, the machine is simflar in operation to other rotary machines whose princlple of operation is shown in Figure 7 and explained below.

The puI1-down cam (C) guides the lower punches to the bottom of their vertical travel, allowing the dies to overfill. The punches then pass over a weight-control cam (E), which reduces the fill in the dies to the desired amount. A blade on the Iarger of the two star-shaped rotors fills the die and another blade renoves excess granulation. Next, the lower punches travel to the lower compression roll (F) while simultaneously the upper punches ride beneath the upper compression roll (G). The upper punches enter a fixed (usually) distance into the dies, while the lower punches are raised to Bqueeze and compact the granulation within the dies. To regulate the upward movement of the lower punches, the height of the lower pressure roll is adjusted. After the moment of compression, the upper punches are withdrawn as they follow the upper raising cam (H); the lower punches ride up the cam (I), which brings the tablets flush with or silghtly above the surface of the dies. The exact position is determined by a threaded bolt called the ejector knob $(J)$. The tablets strike a sweep-off blade and slide down a chute into a hopper which feeds a vibratory conveyor. At the same time, the lower punches re-enter the pul1-down cam (C) and the cycle repeats. (5)

\section{PACKAGING}

The of tablets obtained from the tableting operation are packaged, along with placebo tablets, in circular packs. The machinery which produces the circular packs is proprietary. The discussion of the packaging process wild, therefore, be general in nature.

The packaging room at $O F C$ is physically divided into two parts. The first part (filling) is physically separated and environmentally isolated from the second by a wall with two doors, one on each side of the conveyor. The latter passes through a window to the second part of the rootin (called packaging). 


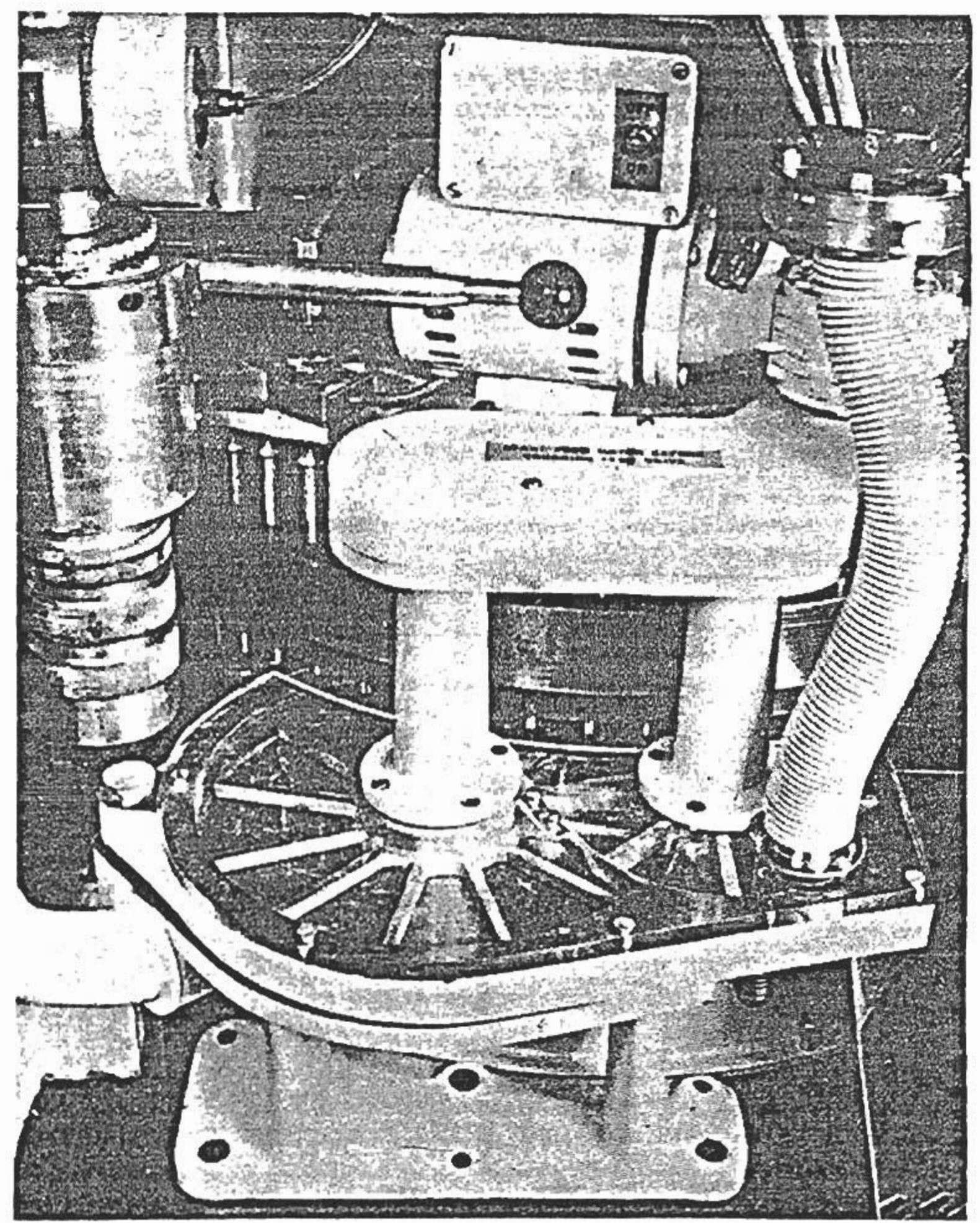

Figure 6. Manesty Force Flow Feeder (Ref. 1) 


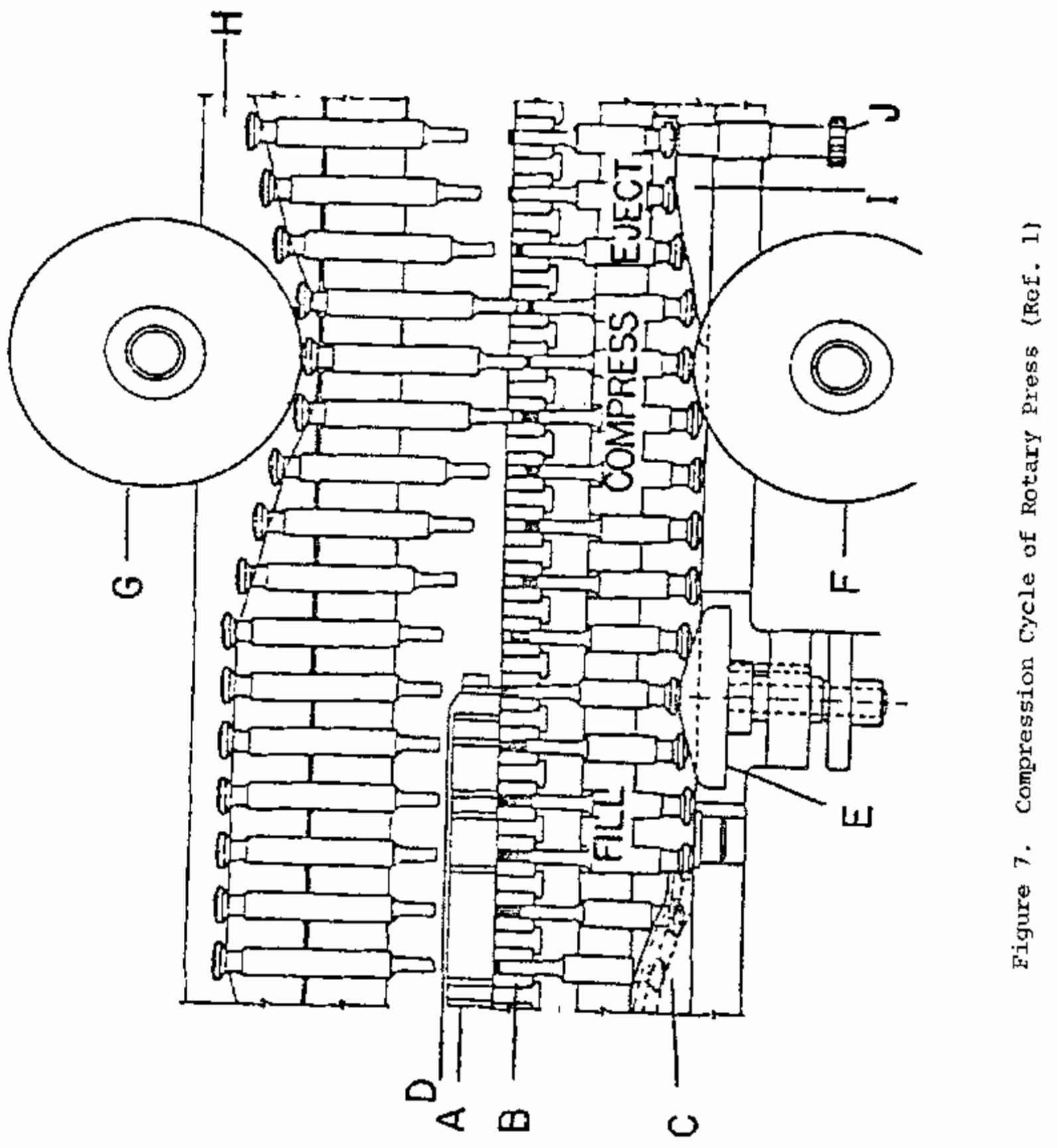


One line tender and three packers operate equipment and perform various quality control functions in the room where pack filling occurs. The line tender's duties include 1) making adjustments on process control equipment, 2) helping the packers in troubleshooting line problems, and 3) making sure that the hoppers are filled. Two packers are always at the second belt conveyor inspecting the individual packs. The ones which are defectlve (missing or broken tablets) are renoved from the conveyor and discarded into a cardboard box. The third packer stands in front of the tablet feed chutes and inspects the columns of tablets for defective ones. These are rewoved by vacuum applied through a small probe attached to a flexible hose. The three line packers switch duties periodically during the shitt.

The pack-filling operation is followed by other packaging operations such as additional quality control, addition of literature to the pack, and packing the small packs into larger boxes for shipping. 
POTENTIAL HEALTH EFFECTS AND SOURCES OF EXPOSURE

Health hazard controls have been implemented at this facility for control of inhalation exposure to substances which are biologicaliy active ln low concentrations. Researchers at OPC have determined that there is very l1ttle likelihood that these materials could be absorbed through intact skin. A summary of toxicological data on these substances may be found in Reference 2 under accession number RC 8925000 for EE, RC8960000 for MES, and RC8975000 for NOR. No Federal standards for exposure are in effect at this time. However, many of the companies which handle these materials bave internal guidelines as to acceptable levels of exposure.

In the following paragraphs, the potential sources of exposure in each step of the manufacturing operations will be qualitattvely described. The description will use the terintinology and approach followed by Hemeon ${ }^{(3)}$ in analyzing the mechanisus by which contaminants are generated and dispersed 1 n the workplace. The potential sources of exposure are those which in the absence of controls (engineering, proper work practices, and PPE) may result in potentially harmful exposures.

The process of weighing the active Ingredients involves scooping the pure material from their shipping packages into smallex containers lined with plastic bags. The pulvation action (or dust generating mechanism) here 1nvolves fine dust particles (of the order of 40 microns or less) entrained into the volume of air (airflow) released by the sudden compaction of the powder which was released from the scoop. The amount of dust generated depends upon the total mass of powder in the scoop, the distance of fall, and level of powder in the container which is being filled. Also, the insertion of the scoop into the container full of actives would also result in dust generation by the same mechanism (sudden compaction of the powder). However, the strength of this source is not as large as that from releasing the actives from the scoop.

When actives and excipients are mixed in the processing area, a number of sources may be visualized. The addition of mestranol or ethynylestradiol to 
the mixing tack could cause small amounts of these actives to be suspended in the air above the solvent $a s$ a result of the shearing action induced by the morton of the particles relative to the air. The same can be said of the dumping of norethindrone into the top of the V-Blender.

After wet mixing and drying have been completed, the active batch is dumped into the capsule. The falling mass of particles would 1nduce an alrflow in the general direction of solids flow. This ast which contains flue farticles "bounces" of the bottom of the receiving vesse1 and moves in the upward direction. An additional amount of dust would be entrained in the air displaced by powder fit the receiving container. Some of this dust created by the dumping process does escape where the capsule mates to the $V$-Blonder.

In the tableting operation, the most significant source of exposure would to the compression of tablets at the two pressure points. The change in tulk density results in a certain amount of air to be driven out which would also entrain some fine powder. The forceflow feed system also generates winor dust emissions resulting from the relatively small amount of compaction that takes place as the powder is beaten about by the rotors and shearing action of the rotary head; the press is designed to control/capture this dust. Finaliy, if tablets were not dedusted, dust may be suspended as the tablets fall irto the receiving container. The mechanism for the generation of dust io this case would be the dispersion of fine powder into the alrstreat generated by the tablets (in free fall) and fine particles which escape that girstream near its periphery and becone suspended in ambient air. This airstrean wonld be deflected when intercepted by the bottom of the. receiving container or the mass of tablets already there.

Much less dust is generated in packaging relutive to processing and tableting. The potential sources of exposure there include the filling of hoppers with tablets and conveying of the tablets frow the hoppers to the feed chutes. 
The objectives of the 1 -depth survey were to characterize and document the health hazard controls that have been Implemented at OPC's stero1d (OC tablet) manufacturing operations. The characterization included:

- observations of the manufacturing operations to qualitatively determine the potential sources of exposure to sterofds.

$\circ$

Assessment of the role of engineering controls in reducing exposures.

0

Observation of work practices and obtaining descriptions of worker training programs.

$\circ$

Conducting air monitoring to determine steroid levels outsioje personal protectlve equipment. These levels represent hypothetical exposures which would occur when only the englneered safeguards and work practices are operating.

$\circ$

Observation of the types of personal protective equipment in use.

Ventilation is an important engineering control at this site. Air velocity (and airflow) measurements were conducted to deteralne the capture velocity fields of the local exhaust systens at various potential sources. A Kurz Model 441 anemoneter was used for this purpose. Measurements of total atr supplied and exhausted in each area of interest were not made because OPC-supflied data were deemed adequate.

Air monitoring of steroid concentration levels in each manufacturing arta consisted of area samples at previously agreed upon locations and was mainl: performed to determe the level of agreement tetween NIOSH and OPC sampling and analytical procedures. Data on concentration levels in the breathing zone outside respiratory protective equipment vere supplied by OPC. The methods used by NIOSF for analysis of the materials of interest are detalled in Appendix A, Eriefly, air is drawn at a rate of 3.00 ipt through a 37 mu 
Teflon filter millipore FALP 37000 nounted 1 a cassette. The filters were desorbed with acetonitrile and the extract analyzed by high perforwance liquid chromatography (HPLC). The limit of quantitation (200) for this procedure is 50 nanograms per filter. Sidemby-side area samples were obtained by conpany and NIOSH investigators, and these samples were analyzed independently, OPC enploys a similar air sampling procedure. Eowever, the filters are snalyzed by radioimanoassay (RIA) as described in Appeodix A. The Lop for che RIA technique is 100 picograms per filter.

Work practices were observed whlle the workers performed chatr job duties and operated process equipment, and whlle they donned or removed protective clothing and respiratory protective equipment. 
HAZARD CONTROL TECHNOLOGY

GENERAL CONSIDERATIONS

The hazard control techniques of interest are: 1) engineering controls including 1solation, ventilation, and automation; 2) work practices which result in lower exposures; 3) monitoring of worker exposures and their health to detect and correct problems as they occur; and 4) personal protective equipment that is effective in further reducing exposures to levels that are constdered acceptable by the company.

\section{ENGINEERING CONTROLS}

Preweighing of Ingredients

The exclpients are preweighed into liber drums lined with plastic bags at a location remote from the sterold facility. They are brought to the material staging area imodiately before $a$ batch is to be mixed. The operation of preweighing of exciplents was not observed. However, it may be presumed that the health hazards associated with preweighing of exciplent are minor and that the controls are not as stringent as those employed when handling steroids.

Active ingredients are preweighed in the preweigh roow within the confines of a Type A hood manufactured by the Baker Company. Figure 8 is a front view of the hood.

A1r velocities at the hood face averaged approximately 50 fpm (using the cotating vane anemometer) so that a total of approximately $620 \mathrm{cfm}$ of air is moved through this hood. The design airflow through this hood is 575 cfm. The exhausted aft is ducted to the dust collector, an American Alr Filter, FAER, pulse unit, which has a rated particulate filtration efficiency of 99.9 percent at $1 \mathrm{um}$. The capture characteristics of the hood are such that an air velocity of $100 \mathrm{fpm}$ is obtalned at the front end of the balance. This $1 \mathrm{~s}$ judged adequate to capture fine dust that may be generated by transferring ingredlents from one container to another. of course, when the worker stands 


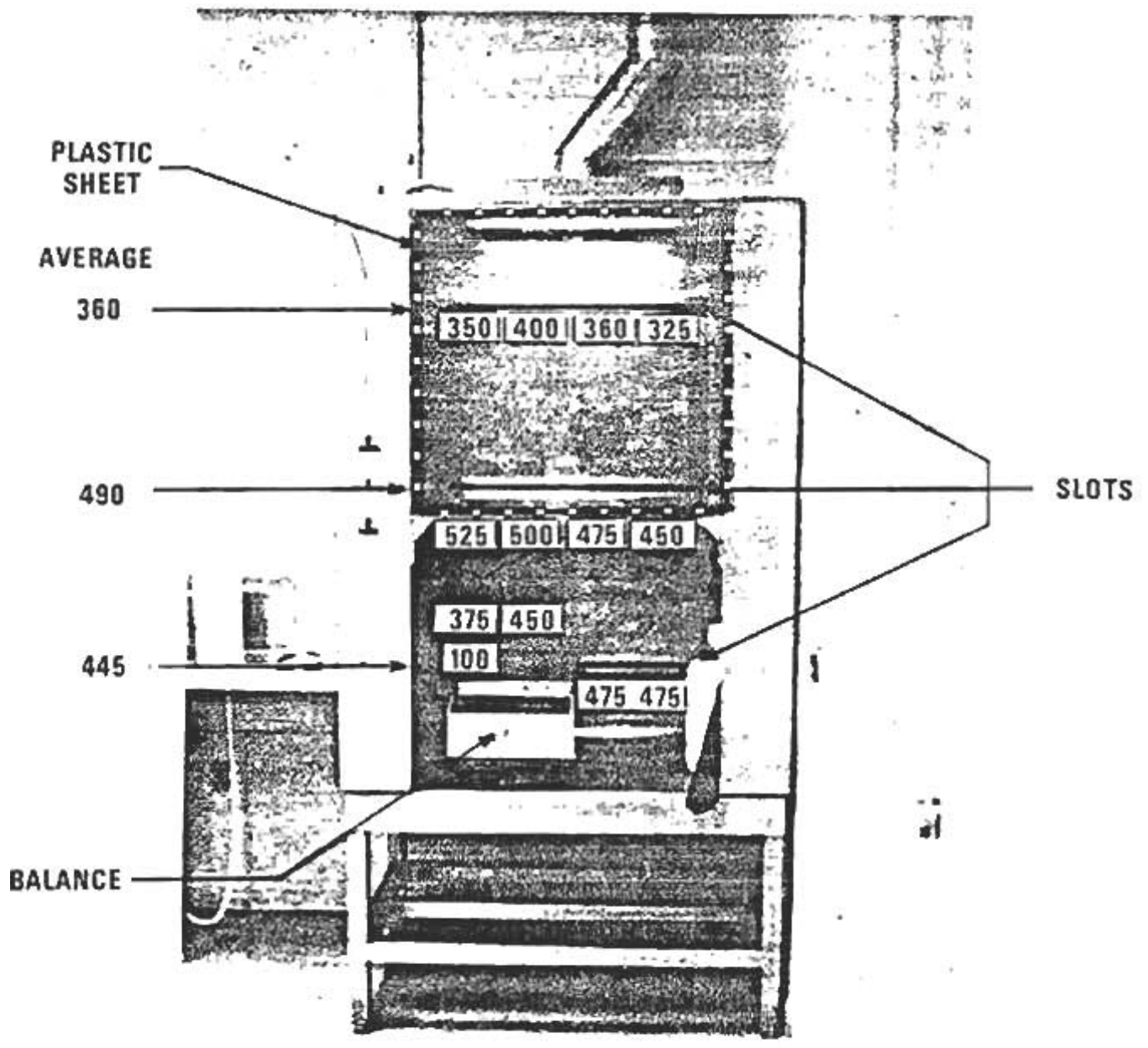

Figure 8. Front View of Preweigh Hood Note: Numbers Indicate Local Velocities in $\mathrm{fpm}$ 
In front of the hood, the air velocity field to his immediate left and right are altered. However, the streamlines would be expected to reform and produce about the same capture velocities at the critical pointa.

A plan view of the preweigh room is given in Figure 9. Air is supplied to the room at a rate of 9.0 room volumes per hour (RVPE) and exhausted (through the hood) at the rate of 11.3 RVPH. Thus, a negative pressure related to its surroundings exists in this room.

If any of the two access doors is open, a switch attached to the door will catse the motorized dampers, which control air stpply, to be closed.

Granulation

Excipients are transferred to the $V-B$ lender from theis containers in the material staging roon using the VAC-UMAX system shown in Figure 2 , thus isolating the technician from the processor room. When compared to direct dumping of the materials, use of this transfer system drastically reduces the dust generation rate. A canopy hood 1s used to capture dust at the location where the wand is used to empty the drums of excipients. This canopy hocd also constitutes the only point where the afr is exhausted from the room at the rate of 9 RVPH. The air stpply is distributed from two celing diffusers at the rate of 7.5 RVPH. Thus, a negative pressure relative to its surroundings exists in this roon.

Norethindrone is added to the blender directly. Mestranol or ethynylestradiol are dissolved in the granulating liquid which is premeasured and placed in the mixing tank before active ingredients are added. General dilution ventilatton is provided in this room as shown in Figure 10. The supply and exhaust grilles (except for air exhausted to the dust collector) are at ceiling level. While at first glance it may be thought that locating the exhaust grilie at ceiling level may cause bypass, company officials enphasized that the supply grilles are designed to deliver the air supply to within a few feet of floor leve1. Air at the rate of 1.6 RVPH is exhausted to the dust collector and 4.1 RVPH is exhausted to the air handing system through the 


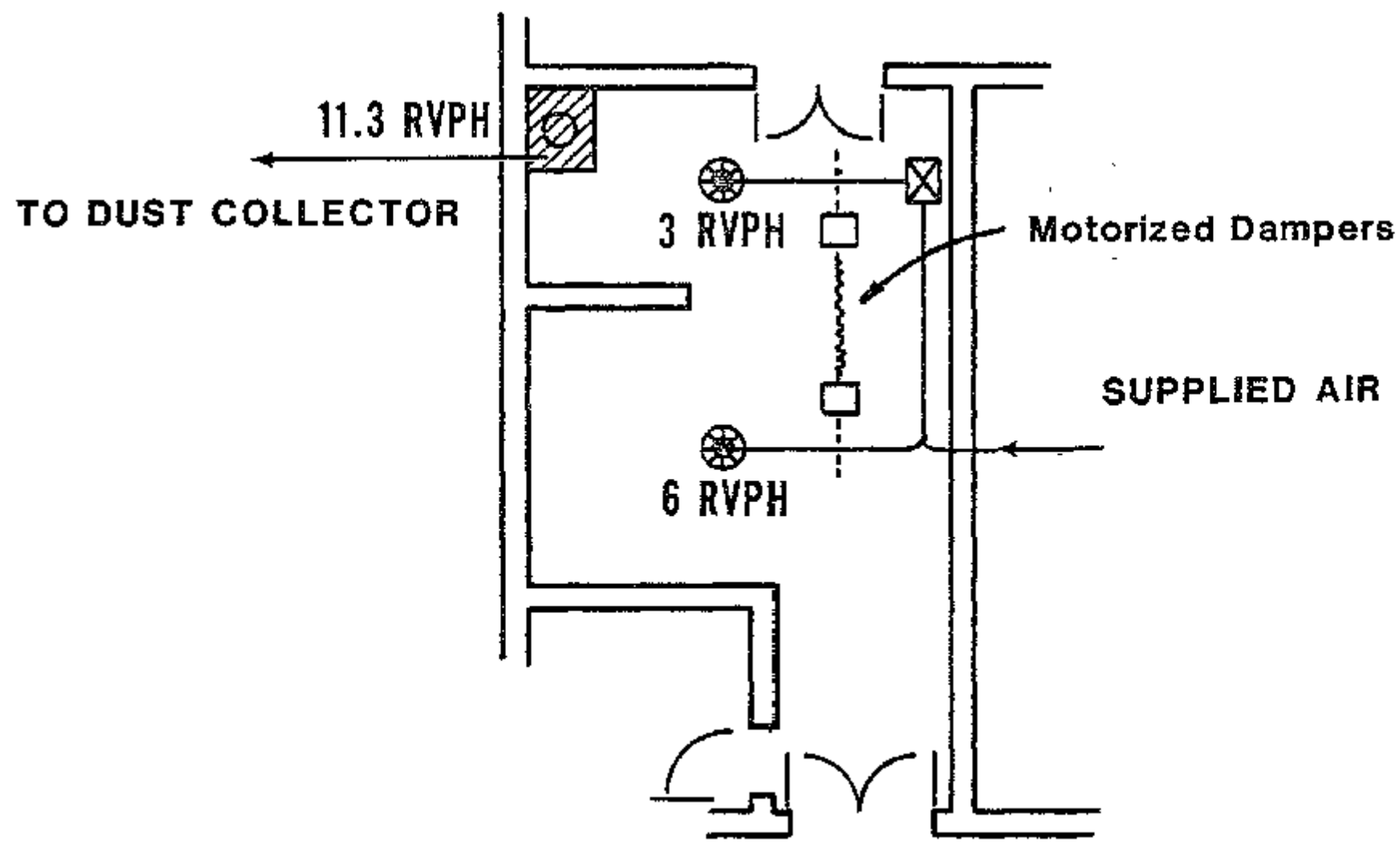

Figure 9. Plan View of Preweigh Roon and General vertilation Scheme 


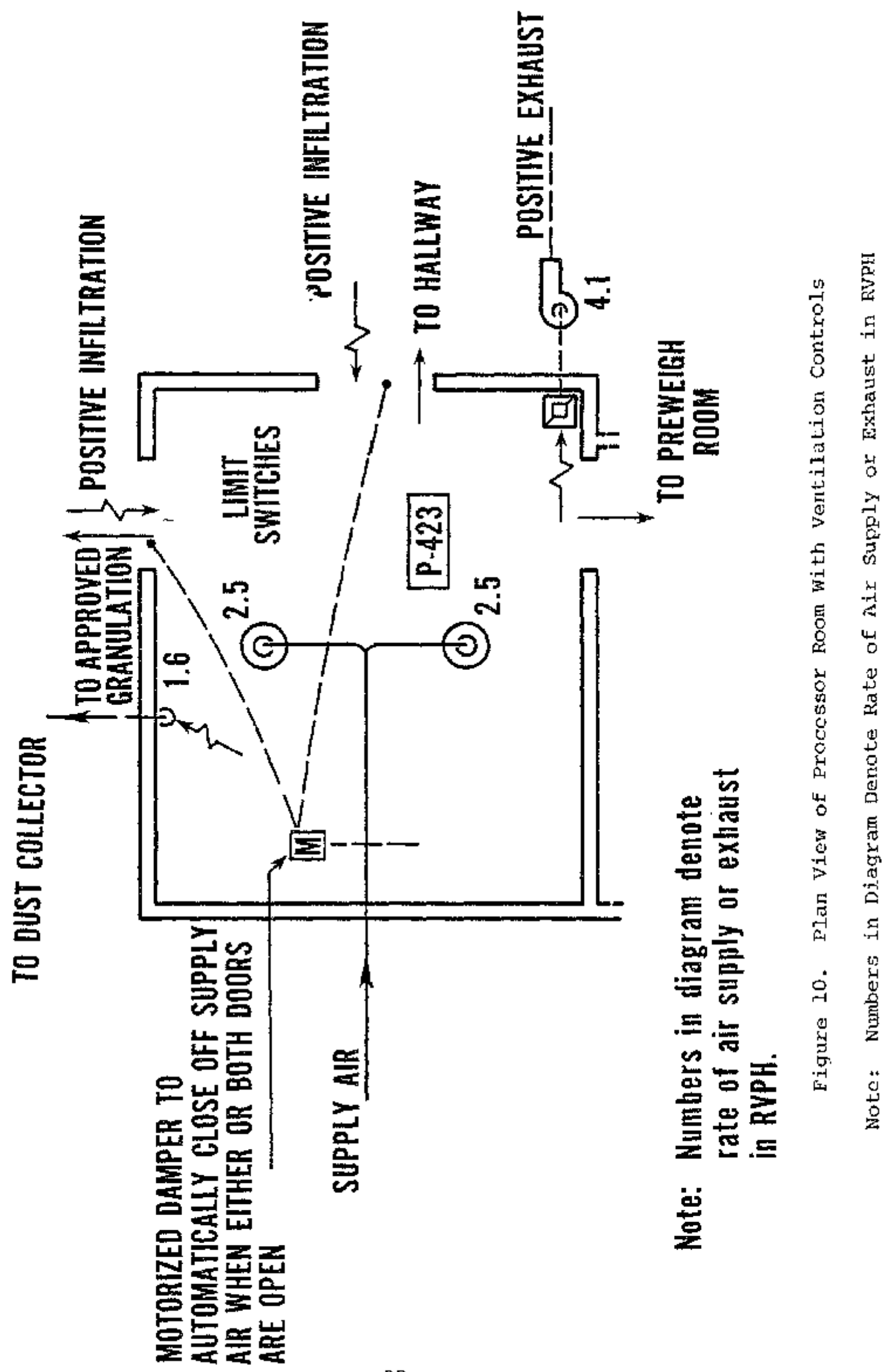


grille in the ceiling. Alr is supplied at the rate of $5 \mathrm{RVPH}$ through the two supply grilles in the ceiling. The notorized dataper shuts off the air supply when either the double door leading to the hallway or the one leading to the room where approved granulation is stored or both are opened. Switches, located at these doors, activate the motorized damper. Shutting off the a1r supply when the doors are opened has the effect of preserving the principle of positive atr infiltration into the room where the processor is located.

The air exhausted to the dust collector is used as a vacuum source for the mobile local exhaust semiclreular slot hood used to control dust when dumping the dry granulation from the blender to the capsule. A plcture of the mobile slot hood appears in Figure 11. Measurements of the capture velocities of this hood were not possible. However, when using this configuration to achieve dust control, the desired control velocities (between 75 and 100 fpm) at any given distance, for example at a distance of 6 inches from the hood face, may be obtained by adjusting the tota1 alrflow exhausted.

The process of granulation as carried out at OPC may in itself be considered an engineering control since the number of transfer points (or processing steps which have a potential for dust generation) have been reduced from about 7 or 8 for less advanced processing systems, to only 2, The two points are the addition of active ingredients and the dumping of dry granulation.

There are additional safety devices in the blender area. Access to the immediate vicinity of the blender is restricted by two gates (one in front and one in back of the blender) to prevent the possibility of workers being struck by the rotating blender. The gates are equipped with electrical switches which prevent them from being opened unless power to the blender is off.

AI1 electrical equipment in the blender area is of the explosionproof-type and designed for use in hazardous locations where explosions of fires may occur as a result of 1 ) the buildup of air concentrations of the granulating liquid in case of failure of the ventilation system or 2) the ignition of the air/vapor mixtures by sparks generated in electrical equipment in the event of spillage of the granulating liquid. 


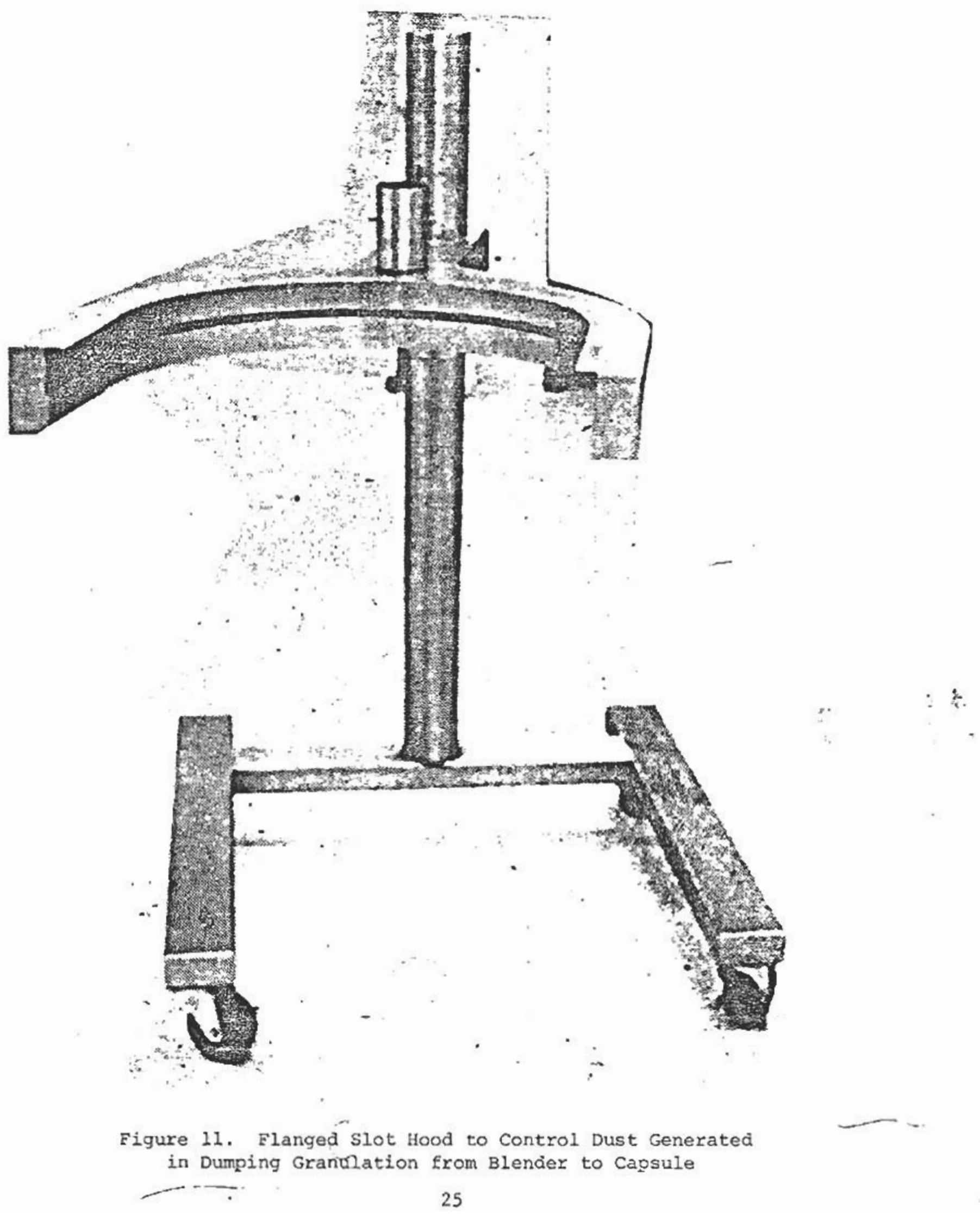


Tableting

The engineering controls in this area consist of 1) a granulation delivery system that is totally enclosed and 2) general and local ventilation.

A capsule containing granulation is wheeled into the tableting room on a bolly from the approved product storage area. It is raised, inverted, and positioned over a closed chute leading to the feed hoppers of the press by means of an electric hoist wounted on a monorail suspended from the celling. The capsule is bolted to the chute with a gasketed flange which prevents product leakage at this point. Flow from the capsule to the press is controlled by a butterfiy valve in the capsule and closed screw conveyors which deliver the granulation to the two feed hoppers at the top of the press. The delivery system is shown schematically in Figure 4. The rotary head of the Manesty press is enclosed by four double glazed glass panels, one on each side as shown in Figure 4.

The tableting machine and peripheral equipment are ventilated by several hundred cfm. The two pressure points, where the potential for dust generation is at a maximum, are ventilated by one "slot" hood which is about 2 by 0.5 1aches. An average velocity of aboul $500 \mathrm{fpm}$ was measured at one of these slots. The rotary head enclosure 15 ventilated at two points as shown in Figure 4. The alrflow in these two pipes is estimated at between 75 and 150 cfm. Finally, air is exhausted from a plenum directly below each of the two vibratory conveyors/dedusters on the left and right sides of the machine. As a result of this exhausted alr, "contro1" velocities on the order of 300 feet per minute are achieved at point (A) where the tablets exit the rotary head enclosure, 100 fpm directly above the partially open area (B) where the tablets enter the conveyor, and about 100 fpm at the open area (C) where the tablets exit the conveyor. All these polnts are marked on Figure 4.

The general ventilation scheme in the tableting room $1 \mathrm{~s}$ shown 1 n Figure 12. Air 1 s supplied at the rate of 20.7 RVPH of which 15.8 RVPH are distributed through grilles 1n the celling and about 5 RVP are used to ventilate the area immediately above the tableting machine in conjunction with 6.75 RVPH that is 


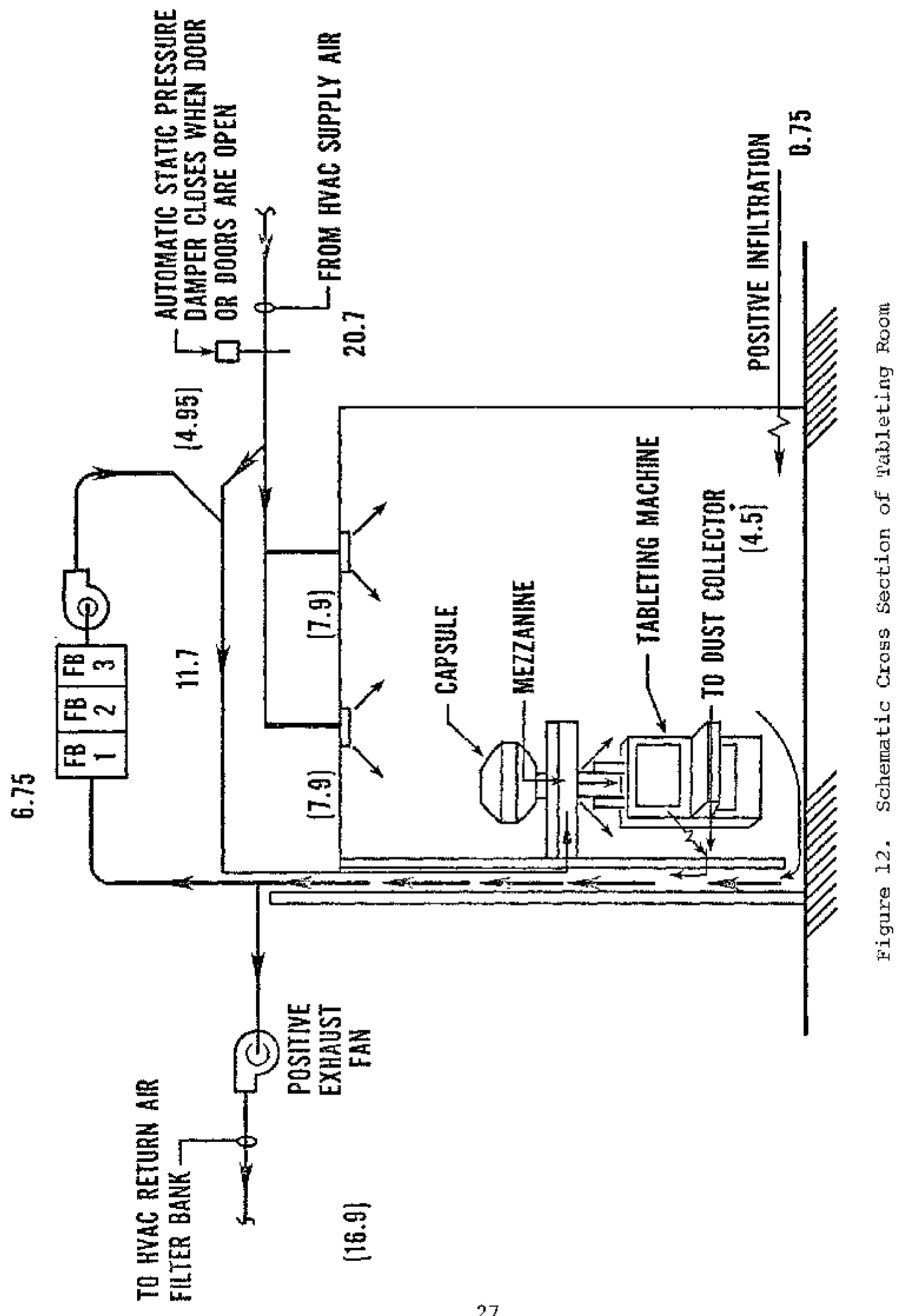


recycled after removal of dust. About 17 RVPH are exhausted to the air handing system through a slot at floor level while 4.5 RVPH are exhausted to the dust collector from the local exhaust devices that are associated with the cableting machine and previously discussed. A portion of the exhausted air is recycled and dust is removed by 3 fllter banks in series. The first two consist of "prefilters" while the third is a HEPA filter.

Under normal condtions, the doors to the roon are closed. An air balance around the room indicates that more afr (about 0.75 RVPH) is exhaustad than supplied in order to maintain a positive infiltration into the room. If a door to the room in opened, switches attached to the door would cause the motorized supply alr damper to close so that positive infiltration of air from the corridor is maintained.

Packaging

There are a nuber of local exhaust ventilation controls incorporated into the circular pack fflijng machine. The three hoppers containing oC and placebo tablets are covered and are exhausted at an estiated rate of 15 cfm each by "elephant trunk" hoses that are attached to the covers. The three vibratory conveyors which transfer tablete from the hoprers to the device which feeds the chutes with tablets are ventilated at en estisated rate of 25 cfta each. The conveyors are covered with rectangular hoods through which the air is exhausted at an estimated rate of $25 \mathrm{cfm}$.

Air is exhausted from the enclosed space between the end of the conveyers and the device which feeds the chutes at an estimated rate of $100 \mathrm{cfm}$. A1r velocities in the range of 100 to 150 fpr were measured in the annular spaces between stattonary and moving parts. The space in front and in back of the tubes connecting the chutes to the "blocks" which positively feed the individual circular packs is ventilated by two small circular hoods at an estimated rate of $120 \mathrm{cfm}$ through each. Control (air) velocities between 50 and 80 fptu were measured in an imaginary vertical plane which intersects the horizontal plane of the conveyor. Capture velocities between 30 and $40 \mathrm{fpm}$ 
were measured at the fringes where contaminants are not very likely to be dispersed.

Clean air is supplied to the filling room from four grilles in the ceiling at a rate of 12.0 RVPH. Air is exhausted from the room to the air handling system at a rate of 10.2. RVPH from two exhaust grilles. An additional 4,1 RVPH is exhausted to the dust collector from 3 Iocations. One of these is the manifold which provides local exhaust ventilation at varfous poines $1 \mathrm{~s}$ the pack filling operation. The balance of the air (2.3 RVPH) enters the room through positive infiltration frot the adjacent room where packsging is completed. Similar rates of air supply and exhaust are also used 1n that area.

Air handling systems

Air supplied to and exhausted from the wanufacturing rooms, corridors, and packaging rooms $1 \mathrm{~s}$ handled by one of two central air handing untes. Each air handing unit is similar 1 n design with respect to filters and airflows. These air handing units worklng in conjunction with localized exhaust fans, secondary recirculation air unfts, and a centralfzed dust collector provide the required building ventilation.

AlI sources which are likely to froduce relatively "concentrated" streams are exhausted to the dust collector. These sources include the hood in the prewelgh room, the portable hood used when duming granulation from the blender, local exhaust systems associated with the tableting machine, and those associated with the cireular pack filling machine. The dust collector is a device with a particle filtration efficiency of 99.9 percent with respect to dust particles of 1.0 micron in diameter.

Alr exiting the dust collector is conbined with building return air before treatment and conditioning. The air passes through two prefiltars and one HEPA filter with a removal efflciency of 99.97 percent with respect to particles at 0.3 microns in diameter. A minimum of approximately 10 percent of this building air is exhausted to the outside. Fresh outside air it a quantity silghtly higher than was exhasted is then mixed with the remainder 
(approximately 90 percent). This air is prefiltered, cooled, and HEPA filtered. It constitutes afr retunned to the various areas served by the system. Reheat coilo and humidifiers are installed in the ductwork which serves various rooms.

Access to Processing Areas

Access to alz processing areas (granulation processing, tableting, and prewelghing) is through the locker rooms. The men's locker 1s diagramed in Figure 13. The worker removes his street clothes in the locker roon and dons personal protective equipment which is picked up from the "wet suit" room. The worker then enters processing from the entry door shown 10 the diagram. The worker returas through another door leading to the suit wash, where jets of water remove particulate from the outside surfaces of the suit. The worker proceeds through the air blast to the "wet suit" room where he takes the viny1 suit off and hangs it to dry in an appropriate location. The design ventilation afrflows and air distribution scheme are shown in Figure 13.

WORK PRACTICES

New employees receive oa-the-jcb training and indoctrination in good manufacturing practices (CMP's) and safety. Manuals have been written and these are avallable for use by both new and old employees.

On-the-job craining consists of a gradual introduction of the new worker to the job together with a gradual building of his/her competence. The first t1me that a worker is assigned to a given operation, he/she observes it being perfomed by a senior technician. The second time involves active participation with the senior technician. The third time he/she performs the work while being observed or monitored by the senior technictan. Usualiy, the new worker is able to perform the job duties adequately on the fourth time.

In the area where estrogens are handled, work activitieg are classified with respect to risk of exposure. High risk activities are those which involve slgnificant potential employee exposure. Included in these activities are 


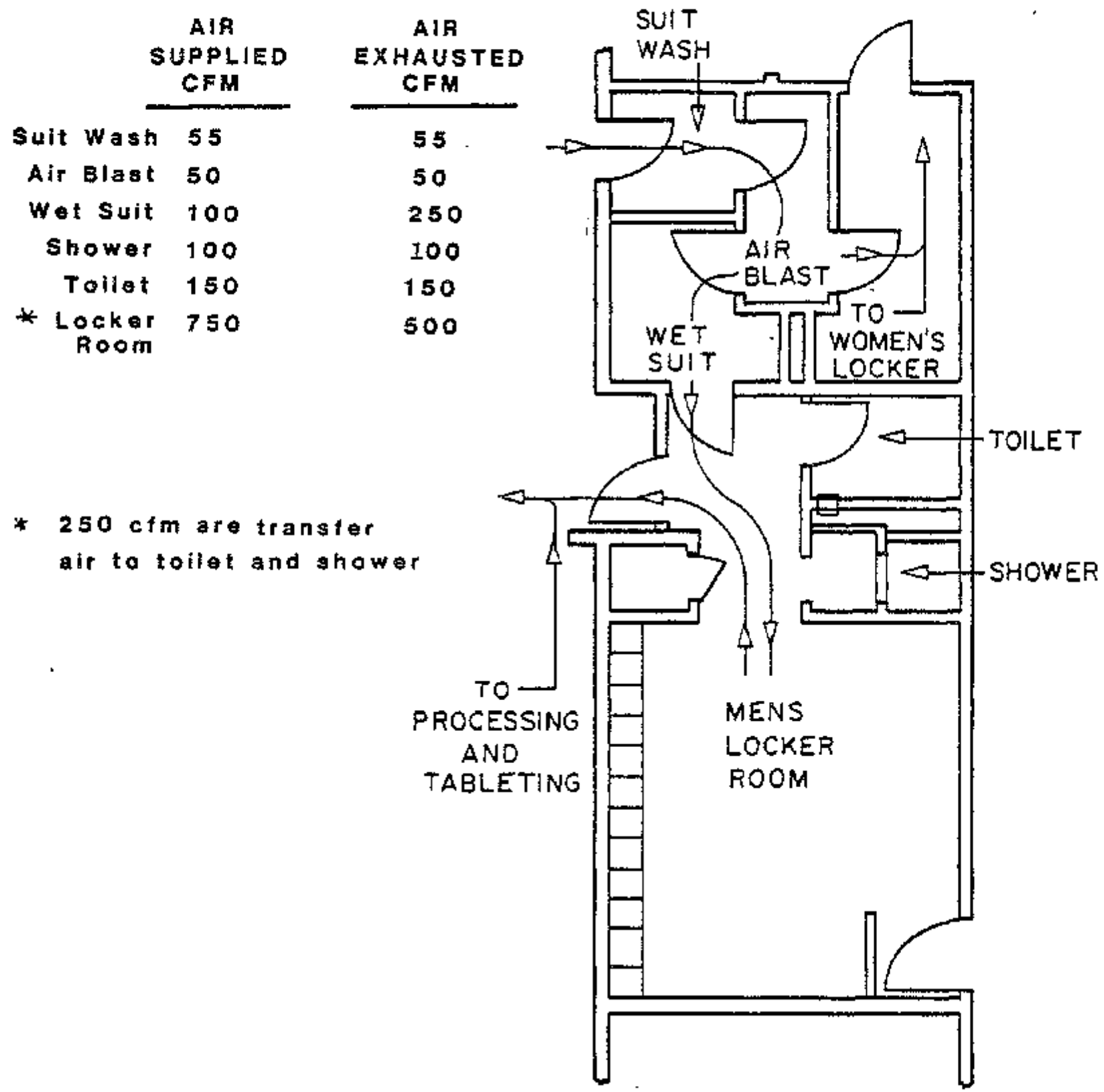

Figure 13. Controlled Access to High Risk Areas 
sampling and analysis of pure act1ve ingredients, preweighing, processing, tableting, and cleanup operations in both processing and tableting. Moderate risi activities are those which involve moderate potential exployee exposure. These include mafntenance activities, filter changing, tablet and granulation analysis, and direct supervision of activities with high or moderate risk. Low risk activities are those which involve a minimal potential for employee exposure. These include tablet inspection, hondling of closed containers, circular pack filing and reclaiming, and fllling line cleanup.

A safety procedure has been written which epecifies personal protective equipment and adtinistrative controls required for each category of risk. A rotation policy in high risk actlvities has been 1mplemented which specifies that for every I0 hours of high risk work, the workers oust stay out of the area and perform entirely different activities for 48 hours. Fertile females are excluded from high risk activities because sterolds are considered to be known teratogens.

In addition to the safety procedure mentioned above, all "batch" sheets include detalled requirements for personal protective equipoent. "Refresher" sessions are held regularly which include the showing of movies on the use, maintenance, and storage of respliators. Also, information on new equipment is presented at these sessions.

Workers in the estrogen area are educated in the health effects of exposure to estrogens by a company physictan and the company safety specialists. They also explain the importance of complying with safety requirements. Work practices are regularly audited by supervisors. Discussions of training requirements and manufacturing operations are held once a month.

MONITORING

Company Activities

Environmental and medfcal monitoring of employees is an ongoing activity at GPC. Environmental monitoring consists of periodically obtaining area and 
personal samples in various areas namely, processing, tableting, and packaging. The samples are collected on 0.5 micron Teflon filters and analyzed by radiolmmunoassay (RIA). A short description of this technique is given in Appendix B. The limit of detection of RIA is 100 picograms per filter. The samples are obtalned at an airflow rate of 4.0 ipu for 6 to 8 hours depending on the duration of the activity. A11 semples are gaalyzed for MES, NOR, and EE. Even though onIy one estrogen (MES and EE) way be present in one sample, the analysis for the other is a quality control procedure.

A plan view of the Ortho-Novtw facility appears 1n F1gure 1. The locations of the general ares samples are shown in the Figure 14. At roat of these locations, the sample is obtalned at a distance of approxidately four feet above ground level and the pump ts hung agalnst the wall. Typlcal area results obtained for the general area and personal samples are shown in Tables 2 and 3, respectively. All concentrations represent 8-hour time-weighted averages (TWA). Therefore, if the duration is lower than 6 hours, the ThA concentration would be lower than that actually measured,

Table 2. Typical Area Sample Results as Previously Determined by OPC

\begin{tabular}{|c|c|c|c|c|c|}
\hline Area/Room & $\begin{array}{c}\text { Location } \\
\text { No. }\end{array}$ & $\begin{array}{l}\text { Avg. MES } \\
\text { Conc., } \\
\text { microgram } \\
\text { per cu.m. }\end{array}$ & $\begin{array}{c}\text { No. of } \\
\text { Samples, } \\
\text { MES }\end{array}$ & $\begin{array}{l}A \mathrm{Vg} . \mathrm{NOE} \\
\text { Conc., } \\
\text { microgram } \\
\text { per cu.m. }\end{array}$ & $\begin{array}{c}\text { No. of } \\
\text { Samples, } \\
\text { NOR. }\end{array}$ \\
\hline Preweighing & 33 & 0.013 & 3 & 0.14 & 3 \\
\hline Processing & $\begin{array}{l}35 \\
36 \\
37\end{array}$ & $\begin{array}{l}1.18 \\
0.053 \\
0.054\end{array}$ & $\begin{array}{l}2 \\
2 \\
2\end{array}$ & $\begin{array}{l}1.60 \\
1.40 \\
2.20\end{array}$ & $\begin{array}{l}4 \\
4 \\
4\end{array}$ \\
\hline Tableting & $\begin{array}{l}40 \\
41 \\
42\end{array}$ & $\begin{array}{l}0.15 \\
0.10 \\
0.01\end{array}$ & $\begin{array}{l}4 \\
5 \\
3\end{array}$ & $\begin{array}{l}2.85 \\
1.74 \\
0.37\end{array}$ & $\begin{array}{l}4 \\
5 \\
3\end{array}$ \\
\hline Packaging & $\begin{array}{l}15 \\
16 \\
17 \\
18\end{array}$ & $\begin{array}{l}0.003 \\
0.008 \\
0.005 \\
0.01\end{array}$ & $\begin{array}{l}1 \\
4 \\
5 \\
6\end{array}$ & $\begin{array}{l}0.02 \\
0.27 \\
0.26 \\
0.41\end{array}$ & $\begin{array}{l}1 \\
4 \\
5 \\
6\end{array}$ \\
\hline
\end{tabular}




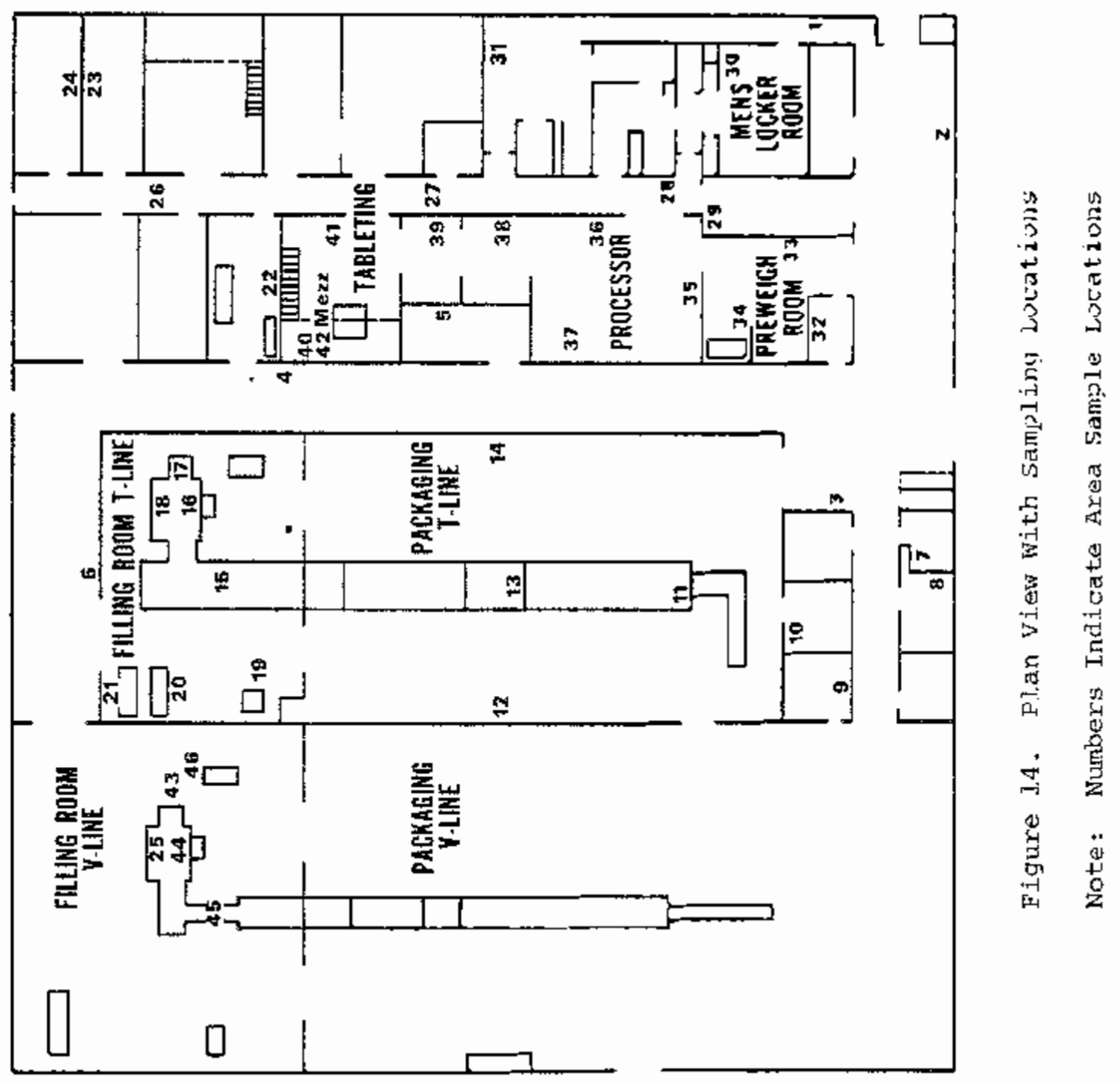


Table 3. Typlcal Breathing Zone Levels for Personal Samples as Previously Determined by OPC

\begin{tabular}{|c|c|c|c|c|c|}
\hline Area/Room & Where Taken & $\begin{array}{l}\text { MES } \\
\text { Conc., } \\
\text { microgram } \\
\text { per cu. m. }\end{array}$ & $\begin{array}{l}\text { No, of } \\
\text { Samples, } \\
\text { MES }\end{array}$ & $\begin{array}{c}\text { NOR } \\
\text { Conc., } \\
\text { microgram } \\
\text { per cu. n. }\end{array}$ & $\begin{array}{c}\text { No. of } \\
\text { Samples, } \\
\text { NOR }\end{array}$ \\
\hline \multirow[t]{2}{*}{ Tableting } & $\begin{array}{l}\text { Inside } \\
\text { Vinyl suit }\end{array}$ & 0.02 & 4 & 0.32 & 4 \\
\hline & Outside & 1.71 & 2 & 31.80 & 2 \\
\hline Packaging* & & 0.02 & 1 & 0.48 & 1 \\
\hline
\end{tabular}

* Actual breathing zone levels would be slightly higher than one-third the values given since three workers rotate this position.

Medical monitoring of employees is conducted routinely. Physical examinations are adminlstered only to workers who may exhlbit symptoms of overexposures to steroids. Every 6 months, each worker fills out a questionnaire to determine whether overexposures noy have occurred.

Mon1toring During NIOSH Survey

Side-by-side area samples were obtained by both NIOSH and OPC during the survey. Personal samples were obtained by $O P C$ for workers in processing and tableting. A1I OPC samples were analyzed by RIA. The personal samples were taken at the breath1ng zone of workers outside of the alr-supplied suit and as such represented environental levels of contaminants with only the englneerlag controls in operation, of course, actual worker exposures would be the outside-the-sult levels divided by the protection factor for the PPE.

General area sample results for the three areas of 1nterest, namely, processing, tableting, and parkaging are presented in Tables 4, 5, and 6 respectively. The general area samples taken by both NIOSE and OPC served to establish the degree of correlation between the two sampling and analytical methods. Because of differences 1 n 1 mits of detection, only norethindrone 
concentrations in the processing and tableting areas could be compared. A statistical comparison of the data at these locations shows that for a log-log plot of the data presented in Table 7 , the slope is not significantly different from unity and the intercept is not signiflcantly different from zero. The correlation coefficient is 0.905 . It is apparent then that breathing zone samples results by ortho (reported $1 \mathrm{n}$ Table 8) would be in close agreement to such samples taken by NIOSH. It is noteworthy that, in general, sample results in processing are about 10 times higher than those in tableting and that the samples in tableting are about 10 times those in packaging.

Table 4. General Area Sample Results in the Processing Room While Mixing ortho-Novum $(\mathrm{R}) 1 / 35$ (NDR/EE)

\begin{tabular}{|c|c|c|c|c|c|c|c|c|c|c|c|}
\hline \multirow[b]{3}{*}{ Date } & \multirow{3}{*}{$\begin{array}{l}\text { Location } \\
\text { Number }\end{array}$} & \multirow{2}{*}{\multicolumn{2}{|c|}{$\begin{array}{l}\text { Sampling } \\
\text { Rate } \\
\text { Liters } \\
\text { Per } \\
\text { Minute } \\
\end{array}$}} & \multirow{2}{*}{\multicolumn{2}{|c|}{$\begin{array}{c}\text { Duration } \\
\text { of } \\
\text { Sampling, } \\
\text { Minutes }\end{array}$}} & \multicolumn{6}{|c|}{ Concentration, micrograns per cu,m. } \\
\hline & & & & & & \multicolumn{2}{|c|}{ MES } & \multicolumn{2}{|c|}{$E E$} & \multicolumn{2}{|c|}{ NOR } \\
\hline & & NIOSH & OPC & NIOSH & $\mathrm{OPC}$ & NIOSH & OPC & NIOSH & $\mathrm{OPC}$ & Nrosh & $\mathrm{OPC}$ \\
\hline \multirow[t]{5}{*}{$6 / 14$} & 28 & 3.1 & - & 557 & - & ND & - & $\mathrm{ND}$ & - & 0.27 & - \\
\hline & 35 & 3.7 & 4.0 & 566 & 561 & $\mathrm{ND}$ & 0.0050 & ND & 0.1092 & 17.81 & 5.35 \\
\hline & 36 & 3.7 & 4.0 & 569 & 576 & ND & 0.0019 & ND & 0.0127 & 3.19 & 0.55 \\
\hline & 37 & 3.7 & 3.0 & 562 & 300 & ND & 0.0774 & ND & 0.1930 & 3.03 & 13.33 \\
\hline & 37 & 3.7 & - & 562 & - & $N D$ & - & ND & - & 3.49 & - \\
\hline \multirow[t]{5}{*}{$6 / 15$} & 28 & 3.7 & - & 519 & - & $\mathrm{ND}$ & - & ND & - & 0.28 & - \\
\hline & 35 & 3.7 & 4.0 & 523 & 532 & $\mathrm{ND}$ & 0.0015 & NiD & 0.3073 & 12.93 & 11.13 \\
\hline & 36 & 3.6 & 3.3 & 530 & 531 & ND & 0.0355 & ND & 0.2768 & 12.50 & 17.23 \\
\hline & 37 & 3.5 & 4.0 & 522 & 532 & $\mathrm{ND}$ & 0.0296 & ND & 0.2429 & 15.45 & 11.41 \\
\hline & 37 & 3.6 & - & 522 & - & $\mathrm{ND}$ & - & ND & $\sim$ & 9.89 & - \\
\hline
\end{tabular}


Table 5. General Area Sample Results While Tableting Modicon (NOR/EE)

\begin{tabular}{|c|c|c|c|c|c|c|c|c|c|c|c|}
\hline \multirow[b]{3}{*}{ Date } & \multirow{3}{*}{$\begin{array}{c}\text { Location } \\
\text { Number }\end{array}$} & \multirow{2}{*}{\multicolumn{2}{|c|}{$\begin{array}{c}\text { Sampling } \\
\text { Rate } \\
\text { L1ters } \\
\text { Per } \\
\text { Minute } \\
\end{array}$}} & \multirow{2}{*}{\multicolumn{2}{|c|}{$\begin{array}{c}\text { Duration } \\
\text { of } \\
\text { Sampling, } \\
\text { Minutes } \\
\end{array}$}} & \multicolumn{6}{|c|}{ Concentration, micrograms per cu.m. } \\
\hline & & & & & & \multicolumn{2}{|c|}{ MES } & \multicolumn{2}{|c|}{$\mathrm{EE}$} & \multicolumn{2}{|c|}{ NOR } \\
\hline & & NIOSH & $\mathrm{OPC}$ & NIOSH & $\mathrm{OPC}$ & NIOSH & $O P C$ & NIOSH & OPC & NIOSH & OPC \\
\hline \multirow[t]{6}{*}{$6 / 16$} & 27 & 3.7 & - & 465 & - & $\mathrm{ND}$ & - & $\mathrm{NB}$ & - & ND & - \\
\hline & 40 & 3.7 & 3.3 & 475 & 473 & $\mathrm{ND}$ & 0.0010 & ND & 0.0030 & 0.31 & 0.1858 \\
\hline & 40 & 3.7 & - & 474 & - & ND & - & ND & - & 0.15 & - \\
\hline & 41 & 3.7 & 4.0 & 468 & 465 & No & 0.0030 & ND & 0.0123 & 0.44 & 0.4301 \\
\hline & 42 & 2.9 & 4.0 & 472 & 468 & ND & 0.0019 & $\mathrm{ND}$ & 0.0081 & 0.52 & 0.3632 \\
\hline & 47 & 3.7 & 4.0 & 480 & 522 & ND & 0.0026 & ND & 0.0114 & 0.44 & 0.4215 \\
\hline \multirow[t]{6}{*}{$6 / 17$} & 27 & 3.7 & - & 473 & - & $\mathrm{ND}$ & - & ND & - & ND & - \\
\hline & 40 & 3.7 & 2.7 & 462 & 471 & ND & 0.0024 & $\mathrm{ND}$ & 0.0082 & 0.44 & 0.2987 \\
\hline & 40 & 3.7 & - & 462 & - & ND & - & ND & - & 0.45 & - \\
\hline & 41 & 3.7 & 4.0 & 471 & 466 & ND & 0.0029 & $\mathrm{ND}$ & 0.0122 & 0.48 & 0.2843 \\
\hline & 42 & 3.7 & 4.0 & 459 & 470 & ND & 0.0019 & ND & 0.0056 & 0.47 & 0.2660 \\
\hline & 47 & 3.7 & 4.0 & 472 & 468 & ND & 0.0061 & ND & 0.0304 & 0.42 & 0.7051 \\
\hline
\end{tabular}


Table 6. General Area Sample Results While Packaging

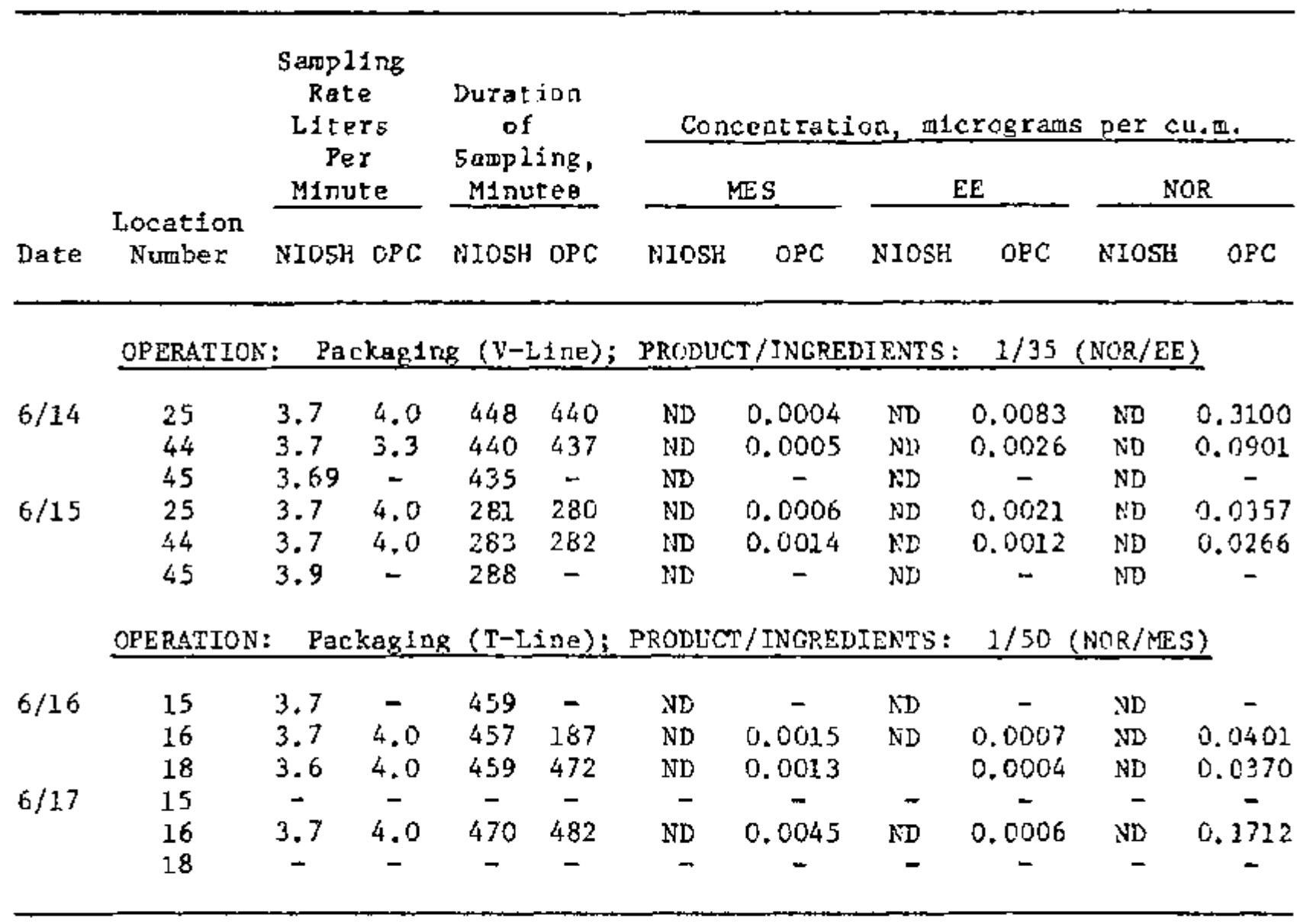


Table 7. Data Used to Compare Sampling and Analytical Results

\begin{tabular}{|c|c|c|c|}
\hline \multirow[b]{2}{*}{ Date } & \multirow{2}{*}{$\begin{array}{c}\text { Location } \\
\text { No. }\end{array}$} & \multicolumn{2}{|c|}{$\begin{array}{l}\text { NOR Concentration } \\
\text { Micrograms per cu.m. }\end{array}$} \\
\hline & & NIOSH & ortho \\
\hline $6 / 14$ & $\begin{array}{l}35 \\
36 \\
37\end{array}$ & $\begin{array}{c}17.81 \\
3.19 \\
3.26 k\end{array}$ & $\begin{array}{r}5.35 \\
0.55 \\
13.33\end{array}$ \\
\hline $6 / 15$ & $\begin{array}{l}35 \\
36 \\
37\end{array}$ & $\begin{array}{l}12.93 \\
12.50 \\
12.67 *\end{array}$ & $\begin{array}{l}11.13 \\
17.23 \\
11.41\end{array}$ \\
\hline $6 / 16$ & $\begin{array}{l}40 \\
41 \\
42 \\
47\end{array}$ & $\begin{array}{l}0.23^{*} \\
0.44 \\
0.52 \\
0.44\end{array}$ & $\begin{array}{l}0.186 \\
0.430 \\
0.363 \\
0.421\end{array}$ \\
\hline $6 / 17$ & $\begin{array}{l}40 \\
41 \\
42 \\
47\end{array}$ & $\begin{array}{l}0.44^{*} \\
0.48 \\
0.47 \\
0.42\end{array}$ & $\begin{array}{l}0.300 \\
0.284 \\
0.266 \\
0.705\end{array}$ \\
\hline
\end{tabular}

* Average of a pair of samples taken at the location.

Table 8. Breathing Zone Levels Outside PPE

\begin{tabular}{|c|c|c|c|c|c|c|c|}
\hline \multirow[b]{2}{*}{ Date } & \multirow[b]{2}{*}{ Operation } & \multirow{2}{*}{$\begin{array}{l}\text { Product/ } \\
\text { Ingredients }\end{array}$} & \multirow{2}{*}{$\begin{array}{c}\text { Sampling } \\
\text { Rate } \\
\text { Liters } \\
\text { Per } \\
\text { Minute }\end{array}$} & \multirow{2}{*}{$\begin{array}{c}\text { Duration } \\
\text { of } \\
\text { Sampling, } \\
\text { Minutes }\end{array}$} & \multicolumn{3}{|c|}{$\begin{array}{l}\text { Concentration, } \\
\text { micrograms per cu. }\end{array}$} \\
\hline & & & & & MES & $\mathrm{EE}$ & NOR \\
\hline $6 / 14$ & Processing & $\begin{array}{c}1 / 35 \\
(\mathrm{NOR} / \mathrm{EE})\end{array}$ & 3.3 & 409 & 0.0043 & 0.1971 & 12.89 \\
\hline $6 / 15$ & Processing & $\begin{array}{c}1 / 35 \\
(\text { NOR/EE })\end{array}$ & 3.3 & 281 & 0.0560 & 0.5974 & 20.83 \\
\hline $6 / 16$ & Tableting & $\begin{array}{l}\text { Modicon } \\
\text { (NOR/EE) }\end{array}$ & 3.3 & 319 & $0.003 I$ & 0.0230 & 0.98 \\
\hline $6 / 17$ & Tableting & $\begin{array}{l}\text { Modtcon } \\
(\text { NOR/EE) }\end{array}$ & 3.3 & 259 & 0.0604 & 0.2200 & 3.76 \\
\hline
\end{tabular}


The small number of personal samples taken in each area does not allow an accurate computation of the mean breathing zone level for each job category and obtaining an accurate estimate of the confldence Ilmfts pertaining thereto. However, the data are useful in qualitatively estimating the order of magnitude of exposures in each location. With these limitations in mind, workers in processing had a geometric mean breathing zone level of 16.4 micrograms per cu,m. whth respect to NoR, while those in tableting had a geometric mean level of 1.92 micrograms per cu,m. during the NIOSR survey. Actual exposures would be $1 / 100$ to $1 / 1000$ those levels as explained 1ater.

All blank samples and samples taken by NIOSH in the locker room showed nondetectable levels of the contaninants. Those obtained by OPC in the locker room showed levels between 0.06 and 0.08 micrograms per cu.m. The levels of mestranol and ethinylestradiol were between $1 / 30$ th and $1 / 1000$ th those values.

\section{PERSONAL PROTECTIVE EQUIPMENT}

Workers performing high risk activities don air-supplied vinyl suits and disposable rubber gloves. The vinyl suits have overshoes attached. The worker exits the high risk area through the suit wash where jets of water wash the dust off the suit before it is taken off.

For moderate risk activities, the worker dons a disposable suit, rubber gloves, and shoe covers. A respirator which is approved for dusts, fumes, and wists having a TIV legs than $0.05 \mathrm{mg}$ per cu.t. is also worn.

Workers in low risk activities wear disposable rubber gloves and disposable dust respirators approved for protection against fibrosis and pneumoconiosis.

Air-supplied suits have an estimated protection factor of 2000 or nore. 4 Achleving the higher levels is dependent upon malntaining the outside as well as the inside surfaces of the suit free from contamination. Also important is mafntaining the clean air distributfon and delivery hoses and associated connect/dsconnect fittings free from contamination. Data reported in Table 3 
geem to Indicate that the air-supplied vinyl suit has a protection factor of 100. 


\section{CONCEUSIONS}

The OC tablet manufacturing operations at OPC may be consldered state-of-the-art technology. A system of health hazard controls has been implemented to reduce worker exposures in processing, tableting, and packaging. The important englneering controls include general and local exhaust ventilation for all three operations, a reduced number of material transfer operatlons $1 \mathrm{n}$ processing, and an enclosed powder dellvery system in tableting.

Sultable work practices are attained through on-the-job training for new workers in addition to emphasizing the safety aspecta of each job. Batch sheets for cach product specify personal protection required through each step of the operation. Health hazards are explained to the workers by a company physician and the safety specialists.

Envirommental and medical wonitoring of employees is performed routinely, Employees are required to fill out medical questionnalres every 6 months. A physical examination is administered to those who exhibit symptoms of overexposure. Data obtalned by $\mathrm{OPC}$ before the NIOSH survey indicates that Dutside-the-suit levels of 31.80 micrograms NoR per cu. meter and 3.71 mlcrograms MES were measured in the tableting rock. Filling machine workers breathing zone levels outside respiratory protective equipment were 0.48 micrograms NOR and 0.02 micrograms MES per cubic meter. Data obtained by OPC during the NIOSH survey indicate that processing worker's breathing zone leveis ourside the vinyl sult were 16.40 micrograms NoR and 0.306 migrograms EE per cubic meter. 


\section{REFERENCES}

1. Lachman, L., H.A. Lieberman, and J.L. Kanig: The Theory and Practice of Industrial Pharmacy (2nd Edition). Lea and Febiger, Philadelphia (1976).

2. Registry of Toxic Effects of Chemical Substances, R.J. Lewis, Sr., and R.L. Tatken, Editors, Vo1. 2, DHHS, PHS, CDC, NIOSH (February 1982).

3. Hemeon, W.C.L.: Plant and Process Ventilation. Industrial Press Inc., New Yoxk (1962).

4. Pritchard, J.A.: A Guide to Industrial Respiratory Protection. I.S. DHEW, PHS, CDC, NIOSH, June 1976. 
APPENDIX A

ANALYTICAL PROCEDURES 


\section{ANALYTICAL PROCEDURES}

\section{HIGH PERFORMANCE LIQUID CHROMATOGRAPHY}

The procedure decribed below outlines a typical amalysis of air samples by high performance liquid chromatography (RPLC). This procedure is concerned with the synthetic steroids mestranol, sorethindrone, and ethinylestridiol.

The samples are typlcally extracted with acetonitrile and aglcated on a sonic bath at $60^{\circ} \mathrm{C}$ for 2 hour. The samplea are filtered through Falp filters, concentrated by solvent evaporation, and analyzed by HPLC.

The HPLC condtions are as follows:

Column - Waters Radial Pak A in a radial compresslon module Solvents - 40 percent acetonitrile/60 percent water isccratic Flow rate - $3 \mathrm{~mL} /$ min

The eluting peaks are measured by two UV detectors and one fluorescence detector in serles. The WV detectors (Waters 450 ) are set at 190 nin for detection of norethindrone and $254 \mathrm{~nm}$ for decection of mestranol. The fiuorescence detector is a Schoeffel FS970 set at 210 ntm excitation with a 340 aII emission filter.

\section{RADIOTMAUNOASSAY}

The filters are extracted with a sultable solvent (e.g., diethyl ether) and an aliquot is placed in assay tubes. Appropriate antiserum solution and a radioactive tracer are added to samples and standards.

After thorough mixing and incubation, bound and free steriods are separated, and the bound steriod i.s placed in scintillation vials and the radloactivity measured. Suspected contaminants (e.g., progestins) are checked for cross-reactivity since these are ustally present on the sane filters. 